The Production of Power from Blast Furnace Gas. S. H. Fowles. (Electrician, March 26, I920.)--Sir Charles A. Parsons, Franklin medallist, " has estimated that the total available waterpower in the British Isles is only $1 / 2$ million horse-power, and that England possesses only one per cent. of the water-power and $2 \frac{1}{2}$ per cent. of the total coal in the world." The blast furnaces of Great Britain annually waste a million horse-power. The following table compares the old method with the Halberg-Beth type of plant:

Gas ola Method New Method

Gas used per furnace per hour $\ldots \ldots \ldots \ldots \ldots$ I,000,000 cu. ft. $\quad 550,000 \mathrm{ct}$. ft.

Coke per ton of pig iron made .......... $23 \mathrm{cwt} . \quad 2 \mathrm{cwt}$.

Units of electricity generated per furnace per

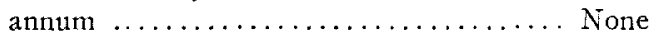

Potash saved per annum ............. None

Flue cleaning costs per annum ......... $£_{\mathrm{I}, \mathrm{O}}$

Coal used per furnace per hour ......... 0.5 ton

Horse-power developed per furnace per hour 600

$6,870,000$

$£ 6,000$

None

0.2 ton

800

G. F.S.

Heat production during luminescence has been studied by E. Newton F .RVEY (Journal of General Physiology, 1919, ii, I37I43). Cypric a hilgendorfi, a small crustacean, contains a compound lucif $\epsilon, n$, and an enzyme luciferase, which oxidizes the luciferin to oxyluciferin in the presence of water and oxygen; this reaction is accompanied by the production of light, and is the cause of the bioluminescence of the living animal. Both the luciferin and the luciferase are soluble in water; and a solution may be prepared containing only one or the other of the two substances. A solution of luciferin was mixed with one of luciferase in a suitable apparatus, and the change in temperature noted. The results indicated that I gram of luciferin liberates less than o.I small calorie during the luminescence which accompanies its oxidation.

J. S. H.

\title{
Duration of Light Emission from a Radiating Hydrogen
} Atom. A. J. Dempster. (Physical Reciew, February, 1920.)Canal rays were shot through a hole from a discharge tube into a second tibe with a much higher vacuum. After moving about 4 $\mathrm{cm}$. beyond the hole the luminosity of the particles died out. From the Doppler effect exhibited by the rays the speed of the particles was found to be $90,000,000 \mathrm{~cm}$. per second. Hence the time required for the light to die away beyond the hole was about five hundred-millionths of a second. The light was chiefly that of the beta line of hydrogen.

VoL. 189. No. $1134-58$ 